\title{
Indoor Residual Spraying Coverage and Acceptability Rates to Control Malaria and the Householders' Reasons of Acceptance or Rejection of Spraying, in South-East of Iran
}

\author{
Mohammad Sakeni, ${ }^{1,2}$ Alireza Khorram, ${ }^{2}$ Reza Majdzadeh, ${ }^{3,4,}$ and Ahmad Raiesi \\ ${ }^{1}$ School of Public Health, Tehran University of Medical Sciences, Tehran, IR Iran \\ ${ }^{2}$ Health Promotion Research Center, Zahedan University of Medical Sciences, Zahedan, IR Iran \\ ${ }^{3}$ Knowledge Utilization Research Center (KURC), School of Public Health, Tehran University of Medical Sciences, Tehran, IR Iran \\ ${ }^{4}$ Center for Academic and Health Policy (CAHP), Tehran University of Medical Sciences, Tehran, IR Iran \\ ${ }^{*}$ Corresponding author: Reza Majdzadeh, Center for Academic and Health Policy (CAHP), Tehran University of Medical Sciences, Tehran, IR Iran. Tel: +98-2166495859, Fax: \\ +98-2166495859, E-mail: rezamajd@tums.ac.ir
}

Received 2015 July 20; Revised 2015 September 3; Accepted 2015 September 9.

\begin{abstract}
Background: Indoor residual spraying (IRS), as one of the malaria control techniques, requires high spraying coverage and acceptance rate by householders, to be effective.

Objectives: The main aim of the study was to assess the spraying acceptability and coverage rates in relation to acceptance and rejection reasons of the IRS program. Also, the householders' perception about IRS benefits and satisfaction with the malaria prevention and knowledge of transmission pathways were estimated.

Materials and Methods: A cross-sectional survey was performed in endemic districts of Sistan-and Baluchistan province (south-east of Iran), in two years of 2013 and 2014. Data were collected by a validated questionnaire, through interviewing 834 household heads that were randomly selected from 40 villages, of four malarial sub-districts. To analyze the data, chi-squire test was performed, by using SPSS software(Version 18). The significance level was set at $\mathrm{P} \leq 0.05$.

Results: A total of 834 households' heads were interviewed, with the mean age of $39.5 \pm 15.4$ years, $73.3 \%$ males and $26.7 \%$ females. The main sources of information, concerning IRS, were health care workers (51.4\%). The IRS coverage and acceptance rates were $96.5 \%$ and $94 \%$, respectively. Of the total number of participants, $95.3 \%$ of householders associated the disease transmission with mosquito bites and reported the use of insecticidal bed nets (90\%) and IRS (74.1\%), as important ways of malaria prevention.

Conclusions: The study showed that IRS coverage and acceptance rates were relatively high, which is essential in reaching malaria elimination. The information on malaria transmission and knowledge prevention measures showed that householders were, to a certain extent, familiar with the malaria control activities conducted by the health care service.
\end{abstract}

Keywords: Malaria, Delivery of Health Care, Disease Transmission, Infectious, Prevention and Control

\section{Background}

Malaria is one of the greatest public health challenges worldwide. Up to one million deaths per year and more than 500 million clinical cases occur in the world (1). In Iran, this disease is one of the major public health problems and the most important vector-borne infection (2). In Tanzania, the malaria disease was responsible for up to one-third of deaths, in children under the age of 5 years and for more than one-fifth of deaths, in pregnant women (3). According to the world health organization (WHO) Global Malaria Program, three important interventions, including diagnosis and treatment of malaria cases with effective medications, insecticide-treated nets (ITNs) distribution and indoor residual spraying (IRS), are imperative for the control and prevention of residents from malaria (4-6).

The IRS, as a highly cost-effective intervention (6) to control malaria on large scale (7), is coating the interior of homes, comprising all walls, roofs and other surfaces, and domestic animal shelters, with chemical insecticides $(5,7)$. Several countries, such as Iran $(2,8)$, have added an IRS program to their malaria control strategy, in line with the WHO recommendations. According to the WHO's global Malaria program, IRS is recognized as a major means of malaria vector control, for reducing and eliminating the malaria transmission $(2,5,7,8)$. Endemic regions can make great advances in malaria elimination, by implementing the suitable IRS interventions, for all populations at risk of malaria, and preserving these programs over time (9). The IRS is basically responsible for the success of malaria control programs $(2,8,9)$. Multiple studies have shown the effectiveness and efficacy of IRS, in reducing malaria vectors and preventing transmission

Copyright (C) 2015, Infectious Diseases and Tropical Medicine Research Center. This is an open-access article distributed under the terms of the Creative Commons Attribution-NonCommercial 4.0 International License (http://creativecommons.org/licenses/by-nc/4.0/) which permits copy and redistribute the material just in noncommercial usages, provided the original work is properly cited. 
of infection, in the nations where it was performed (4-6, $8,10)$. Living in the IRS-intervention houses has a protective effect on transmission of infection (6). For instance, in Zanzibar, IRS reduced the malaria prevalence from $76 \%$ to less than 5\%, during 1957-1967 (9) and also, reduced the malaria incidence by more than $90 \%$, in major regions of tropical Asia and Southern America, through a combination of IRS with other measures, during the eradication program (5). In 2010, IRS protected 185 million people (6\% of the world population) at risk for malaria infection.

Although it is still underutilized in the world, the IRS intervention is increasing globally (9). Studies indicated that IRS can be most effective to control malaria by applying and expanding the IRS to up to $80 \%$ of region's households $(5,8,11)$. In several studies from different parts of the world, the results showed that the IRS coverage rates varied from $27.8 \%$, in eastern Ethiopia (12), to 95\%, in Zanzibar, Tanzania (13).

The IRS Effectiveness processes requires household acceptance (14) and is deeply associated with willingness of households to accept the spraying of residual insecticides, during the spraying campaign (3). Its acceptability varied from location to location (14). For example, in Indonesia, a study showed that approximately all householders reported a willingness to accept IRS for malaria prevention (15), whereas this rate was $97.6 \%$ in Southern Mexico (11), to $29 \%$ - $41 \%$ throughout the study period, in rural Mozambique (16). In Hlongwana et al. study, in South Africa, $29.4 \%$ of the respondents reported that they disliked certain aspects of spraying, because of the discoloring of inner walls of their houses, through spraying the insecticide (1).

The quality and amount of health information and education about malaria that are provided to the community to ensure that people perform the preventive measures, are critical factors, which increase the effectiveness of malaria-control interventions (1). Several studies have reported the good knowledge about the malaria transmission $(1,3,12,13)$. In Hlongwana et al. study, about $93 \%$ of the respondents had heard about the malaria disease and $84.6 \%$ of them correctly related the disease to mosquito bites (1). In Gobena et al. study that evaluated the knowledge of women about malaria, $85.9 \%$ of participants had heard of malaria disease and $56.1 \%$ of them mentioned the malaria transmission through mosquito bites (12).

In order to deliver IRS effectively, several critical factors are necessary, as follows: community awareness and cooperation that influence the effectiveness of IRS programs; IRS acceptability by the local households, which helps to obtain a high level of coverage; informing the households and aware them about the program and its benefits; and implementation of community education (14). Studies have emphasized that improved community knowledge about the malaria disease can increase the personal protective practices amongst individuals at risk (17).
Socio-economic development, such as houses features improvements, is associated with the lower risk of malaria outcomes. Studies showed that residents of modern houses had lower risk of malaria infection and lower risk of clinical malaria, compared to residents of traditional houses (18).

The Sistan and Baluchistan province, South-eastern Iran, is classified as unstable malaria area and has the highest prevalence of malaria transmission in the country, comprising of nearly $42 \%$ - $60 \%$ of the whole malaria cases occurring in Iran. The IRS intervention program has been implemented in Iran and also in that province, since 2003 (8). Despite the substantial advances in decreasing the malaria transmission, over the last years, it yet remained a leading public health problem and the disease has not been eliminated.

\section{Objectives}

The present study was conducted to evaluate the acceptance of implementation of a house-to-house IRS program, in selected villages of South-eastern Iran districts. Also, householders' perception about the benefits, futility, satisfaction and dissatisfaction of IRS program were assessed.

\section{Materials and Methods}

\subsection{Study Area}

The study was conducted during two different time periods of years 2013 and 2014, in four main malaria endemic districts of Sistan and Baluchistan province, south-east of Iran, bordering the neighboring countries of Afghanistan and Pakistan. These districts were chosen as the study regions, because of the high levels of malaria vector mosquito's redundancy that was historically observed.

\subsection{Study Design and Population}

A cross-sectional study model on households was used. All households in the rural of Konarak, Chabahar, Sarbaz, and Saravan districts, south-east of Iran, were included in the study sample. According to the spraying needs assessment, these four districts were categorized as epidemiological malaria foci and the residents, whom were living in the villages of the districts under consideration, were included in the study. In spraying needs assessment, the criteria for including the villages to spraying program were the villages that classified as new probable, new active, old active, and cleared up malaria foci, with population exchange with adjoining malaria-prone regions or countries.

\subsection{Data Collection}

The main instrument of this study was a specific ques- 
tionnaire, with 38 items, including demographic characteristics, such as age, sex, occupation, educational level, family size and knowledge about the malaria prevention and transmission. Also, the questionnaire comprised the variables of IRS coverage/acceptance/satisfaction/dissatisfaction/benefits, informing the householders about the IRS, socio-economic situations, based on the type of the building materials and having electricity (village/house), cooler (air conditioner or evaporative cooler), and television. The questionnaire validity was checked by four experts in epidemiology field, which were familiar with malaria control programs.

The data were gathered through interviewing by health care workers and subjects were asked the questions in the locally used language. To complete the questionnaires, only the interview was done with the household heads or their wives. In the absence of both of them, another household was randomly replaced with. At the beginning of the study, all interviewers had received training course and were justified about the study. Also, during the study, to monitor the process of data collection, the health experts of each district were designated as field supervisors and were responsible that interviewers fulfill the questionnaires, as well. For accuracy, $10 \%$ of the questionnaires were rechecked by field supervisors.

\subsection{Sampling}

In each mentioned districts, 1 month before the seasonal spraying time, the villages were divided into two categories: the villages that need to be sprayed (based on the four defined criteria) and the villages that do not need to be sprayed. The study samples were chosen just from the villages that need to be sprayed and which were listed from the needs assessment form. In each district, the numbers of villages that need to be sprayed was of approximately 120 villages. In four of the districts, the multistage random sampling was used to select 10 villages from the villages list and, finally, 40 villages were included in the study. In each selected village, as one cluster, at least 20 households were randomly selected from the village's households list, to participate in the study. Therefore, in all 10 villages, 200 households were selected. In total, from all four districts, 800 households were selected to participate in the study.

According to the authors' experience, with regard to the above, if an average of $80 \%$ of villages that need to be sprayed, agree to implement the spraying in that villages and in each village, and if $80 \%$ of householders cooperate with spraying implementation, in total, $64 \%$ of whole villages households that need to be sprayed would accept and cooperate to spray $(\mathrm{P}=0.64)$. Because of the study type [a cross-sectional study with $\mathrm{d}=0.064$ (one-tenth of P) and alpha $=5 \%$, based on the following equation], the sample size was calculated at about 200 households, in each village.

$$
n=\frac{\left(Z_{\frac{\alpha}{2}}\right)^{2}(\mathrm{PQ})}{\Delta^{2}}
$$

\subsection{Data Analysis}

The analysis of data was performed by using SPSS software Version 18 (SPSS Inc., Chicago, IL, USA). Descriptive statistical methods were used for demographic data analysis. The nonparametric chi-squire test was used for the statistical analysis of the data. The significance level was set at $\mathrm{P} \leq 0.05$.

\subsection{Ethical Clearance}

The study obtained ethical considerations by ensuring the respondents that their personal information would not be published individually and researchers strove to ensure the participants about the privacy of information. All participants had the opportunity to leave the study, at any time. In this study, there was no biological sampling.

\section{Results}

In the first period of the study, a total of 834 households' heads were interviewed, in all four districts, including $73.3 \%$ males and $26.7 \%$ females. The mean age of participants was $39.5 \pm 15.4$ years. More than half of participants (59.3\%) were illiterate and just $2.1 \%$ were with university degree. The main economic activities carried by the majority of householders were farming and livestock keeping (45.7\%). The average family size was approximately five members. To indicate the socioeconomic status, nearly $88.3 \%$ of villages and $88.7 \%$ of households under study had electricity. About $62.5 \%$ and $54.4 \%$ of householders reported that they had cooler (air conditioner or evaporative cooler), and TV in their houses. Concerning the type of building materials used, the majority were living in mud brick houses (37.1\%) and in the case of livestock shelters material, shed predominated, with $75.4 \%$ redundancy. The highest frequency of houses was in cleared-up malaria foci (26\%). On the time of the study, 1.6\% of householders' heads indicated that, during the last year, at least one of their family members had had malaria disease. The detailed socio-demographic characteristics of householders are presented in Table 1.

As Table 2 shows, $94.8 \%$ of the respondents reported that one day before the spraying, they had received information about the IRS campaigns and the main sources of information were health care workers (51.4\%). During the previous summer, $96.5 \%$ of households were visited by health care workers and offered to spray theirs houses, accounting for $94 \%$ of households and $92.4 \%$ of livestock shelters spraying, implemented at that time. About 93.2\% of respondents reported that spraying of households was useful and 94\% were satisfied about their livestock shelters spraying. 
Sakeni $M$ et al.

Table 1. Socio-demographic and Socio-economic Characteristics of Householders in Selected Villages of Baluchestan Districts, South-east of Iran

\begin{tabular}{|c|c|}
\hline Characteristics & Values $^{\mathrm{a}}$ \\
\hline \multicolumn{2}{|l|}{ Gender } \\
\hline Male & $611(73.3)$ \\
\hline Female & $223(26.7)$ \\
\hline \multicolumn{2}{|l|}{ Age, $y$} \\
\hline$\leq 29$ & $254(30.4)$ \\
\hline $30-59$ & $473(56.7)$ \\
\hline$\geq 60$ & $107(12.9)$ \\
\hline \multicolumn{2}{|l|}{ Education level } \\
\hline Illiterate & $495(59.4)$ \\
\hline Under diploma & $266(31.9)$ \\
\hline Diploma & $56(6.7)$ \\
\hline University & $17(2.1)$ \\
\hline \multicolumn{2}{|l|}{ Main Jobs } \\
\hline Employee & $29(3.5)$ \\
\hline Housewife & $57(6.8)$ \\
\hline Shopper (self-employed) & $35(4.2)$ \\
\hline Worker & $115(13.8)$ \\
\hline Farmer or livestock keeper & $381(45.7)$ \\
\hline Fishermen & $44(5.3)$ \\
\hline Others & $173(20.7)$ \\
\hline \multicolumn{2}{|l|}{ Family Member } \\
\hline$\leq 3$ & $253(30.3)$ \\
\hline $4-6$ & $377(45.2)$ \\
\hline$\geq 7$ & $204(24.5)$ \\
\hline \multicolumn{2}{|c|}{ Having Electricity in Their Village } \\
\hline Yes & $736(88.3)$ \\
\hline No & $98(11.7)$ \\
\hline \multicolumn{2}{|c|}{ Having Electricity in Their Home } \\
\hline Yes & $740(88.7)$ \\
\hline No & $94(11.3)$ \\
\hline \multicolumn{2}{|l|}{ Types of Malaria Foci } \\
\hline Cleared up & $217(26)$ \\
\hline New probable & $200(24)$ \\
\hline New active & $57(6.8)$ \\
\hline Old active & $183(21.9)$ \\
\hline Old inactive & $177(21.3)$ \\
\hline \multicolumn{2}{|l|}{ Building Materials } \\
\hline Cement block & $294(35.2)$ \\
\hline Brick & $15(1.8)$ \\
\hline Stony & $81(9.8)$ \\
\hline Mud brick & $311(37.2)$ \\
\hline Shed & $133(16)$ \\
\hline \multicolumn{2}{|c|}{$\begin{array}{l}\text { Having at Least one Malaria Patient in } \\
\text { Their House (During the Previous Year) }\end{array}$} \\
\hline Yes & $13(1.6)$ \\
\hline No & $821(98.4)$ \\
\hline
\end{tabular}

Table 2. Indoor Residual Sprays and Livestock Shelter Spraying Coverage, Acceptance and Satisfaction Rates ${ }^{\mathrm{a}}$

\begin{tabular}{|c|c|}
\hline Questions & Values ${ }^{b}$ \\
\hline \multicolumn{2}{|c|}{$\begin{array}{l}\text { Receiving Information About IRS (one day Before } \\
\text { the Program) }\end{array}$} \\
\hline Yes & $763(94.8)$ \\
\hline No & $41(5.2)$ \\
\hline \multicolumn{2}{|c|}{ Source of Information About IRS } \\
\hline Health care workers & $414(51.4)$ \\
\hline Malaria officer & $329(41)$ \\
\hline Local council & $37(4.6)$ \\
\hline Mosques' imams & $24(3)$ \\
\hline
\end{tabular}

In the Last Summer, was Your House Visited and did Health Care Workers Offer to Spray Your House? (coverage)

$\begin{array}{lc}\text { Yes } & 804 \\ & (96.5) \\ \text { No } & 30(3.5) \\ \text { If Yes, was Your House Sprayed? (acceptance) } & \\ \text { Yes } & 755(94) \\ \text { No } & 49(6)\end{array}$

If Your House was Sprayed, was Spraying Beneficial?

Yes $704(93.2)$

No $\quad 51(6.8)$

Were Your Livestock Shelters Sprayed? (acceptance)

Yes 743(92.4)

No 61(7.6)

If Yes, are you Satisfied With Your Livestock Shelter Spraying?

Yes $699(94)$

No $44(6)$

a Abbreviation: IRS, Indoor Residual Spraying.

balues are presented as No.(\%).

With multiple choices answers, in malaria transmission and prevention ways knowledge, 95.3\% of householders' heads declared that the disease transmission occurs with mosquito bites and $2.3 \%$ were not familiar with disease transmission. Also, using the insecticidal bed nets (90\%) and IRS (74.1\%) were reported as important ways of malaria prevention. Chemoprophylaxis was the last choice in prevention and just $2.3 \%$ of householders were not aware about the measures of malaria prevention. Approximately $83.6 \%$ of householders reported that the most important benefit of spraying was reduction in malaria transmission and $64.8 \%$ associated it with killing the malaria vectors. The most important factor for livestock shelters spraying satisfaction was mosquitos' elimination (78.1\%) and, between all respondents that were not satisfied, the majority (86.5\%) believed that IRS was ineffective and did not decrease the mosquitoes and insects redundancies. In householders' perception about the futility of IRS program, the majority (75\%) believed that spraying will not reduce the mosquitos. Discoloring of inner house walls by insecticide (60.9\%) was the main reason of refusing the health care workers to spray their houses. In $92.4 \%$ of the households, the triangle sign was installed at the sprayed area. The detailed householder's perceptions about the IRS are presented in Table 3. 
Sakeni $M$ et al.

Table 3. Reported Householders' Knowledge on Prevention and Transmission Mechanisms of Malaria and Their Opinions and Perceptions About the Benefits, Satisfaction, Dissatisfaction and Acceptance of Indoor Residual Spraying and Livestock Shelters Spraying (Multiple Response) $^{\mathrm{a}}$

\begin{tabular}{|c|c|c|}
\hline & Opinions About the Benefits of IRS & Values $^{\mathrm{b}}$ \\
\hline 1 & IRS will reduce the malaria transmission & $590(83.6)$ \\
\hline 2 & Spraying will kill the malaria vector mosquitoes & $455(64.8)$ \\
\hline 3 & Spraying will eliminate the flies and ants & $349(49.7)$ \\
\hline 4 & IRS will lessen the insects' numbers, such as scorpions and bees & $226(32.2)$ \\
\hline \multirow[t]{2}{*}{5} & Others & $2(0.3)$ \\
\hline & Satisfaction Reasons About the Livestock Shelters Spraying & \\
\hline 1 & Spraying will kill the mosquitoes & $435(78.1)$ \\
\hline 2 & IRS will lessen the malaria transmission & $242(43.4)$ \\
\hline 3 & Spraying will reduce the pesky insects (scorpions, flies and bees) & $239(42.9)$ \\
\hline 4 & Does not know & $8(1.4)$ \\
\hline \multirow[t]{2}{*}{5} & Others & $6(1.1)$ \\
\hline & Perception About the Futility of IRS Program & \\
\hline 1 & Spraying will not reduce the mosquitos & $42(75)$ \\
\hline 2 & Spraying does not influence on insects numbers, such as scorpions and bees. & $41(71.9)$ \\
\hline 3 & Malaria is eliminated and IRS would not be useful & $11(19.3)$ \\
\hline \multirow[t]{2}{*}{4} & Others & $3(5.3)$ \\
\hline & Dissatisfaction Reasons About the Livestock Shelters Spraying & \\
\hline 1 & IRS is ineffective and did not decrease the mosquitoes and insects & $32(86.5)$ \\
\hline 2 & Foods and animals movement is difficult to do & $14(37.8)$ \\
\hline 3 & Insecticides may contaminate the forages and toxic forages would make the domestic animals sick & $6(16.2)$ \\
\hline 4 & Bad behavior of sprayer & $6(16.2)$ \\
\hline \multirow[t]{2}{*}{5} & Others & $37(4.4)$ \\
\hline & The Reasons of IRS Refusal (in the Last Summer) & \\
\hline 1 & Discoloring of inner house walls by insecticide & $28(60.9)$ \\
\hline 2 & Difficulty in furniture's movement & $24(52.2)$ \\
\hline 3 & Bad behavior of sprayers & $15(32.6)$ \\
\hline 4 & Malaria is eliminated and IRS would not be useful & $14(30.4)$ \\
\hline 5 & Because of having the cooler (air conditioner or evaporative cooler),there is no need to spray & $11(23.9)$ \\
\hline \multirow[t]{2}{*}{6} & Health care workers did not visit the house for spraying & $10(21.7)$ \\
\hline & Knowledge About the Prevention Ways Against Malaria Transmission & \\
\hline 1 & Using insecticidal bed nets & $742(90)$ \\
\hline 2 & IRS & $609(74.1)$ \\
\hline 3 & Installing nets for doors and windows in house & $396(48.2)$ \\
\hline 4 & Using mosquito repellents & $79(9.6)$ \\
\hline 5 & Spraying the domestic animals shelters & $50(6.1)$ \\
\hline 6 & Home treatment (Using traditional healers) & $43(5.2)$ \\
\hline 7 & Chemoprophylaxis & $35(4.3)$ \\
\hline \multirow[t]{2}{*}{8} & Do not know & $19(2.3)$ \\
\hline & Knowledge About the Transmission Ways of Malaria Disease & \\
\hline 1 & Mosquito bite & $783(95.3)$ \\
\hline 2 & Unhealthy behaviors & $272(33.1)$ \\
\hline 3 & Air pollution & $17(2.1)$ \\
\hline 4 & Water & $8(1)$ \\
\hline 5 & Food & $3(0.4)$ \\
\hline 6 & Do not know & $19(2.3)$ \\
\hline
\end{tabular}


According to the results in Table 4, in 2013, there was a significant association between IRS acceptability with selected districts $(\mathrm{P}=0.001)$. The higher acceptability of IRS was in Sarbaz district (100\%) and the lowest was in Saravan district (80.9\%). The relationship between the levels of acceptance of livestock shelters spraying with selected districts was statistically significant $(P=0.001)$. During 2013 and 2014, in Sarbaz district, the livestock shelters spraying acceptability was higher than in the other districts.

As Table 5 shows, in 2013, the results revealed that there was significant association of IRS acceptability with gender, level of education, householders' job, satisfaction on livestock shelters spraying, IRS effectiveness, types of malaria foci, building materials, home and village electricity, and having cooler (Air conditioner or Evaporative cooler) and TV in their houses $(\mathrm{P}<0.05)$. The highest acceptability was recorded in the female gender (96.2\%). Householders, who possessed an university degree, had higher acceptability rate. In workers, the IRS acceptance rate was lower than in other householders. All householders that were satisfied on livestock shelters spraying and believed that IRS was useful accepted that spraying of their household. There was a significant association between the IRS acceptability with malaria foci $(\mathrm{P}=0.001)$. The acceptance rate in householders that were living in cleared-up malaria foci was higher than reported in another types of foci and the rejection was higher in new probable (21.7\%) and new active (12.2\%) foci. There was significant association between IRS acceptability with the households building materials $(\mathrm{P}=0.001)$. All householders, whom were living in brick buildings (26.7\%) had higher IRS rejection rate. The relationship between the level of acceptance of IRS, with having home and village electricity, was statistically significant $(P=0.04)$. The acceptability rate of IRS in homes and villages without electricity was lower than with electricity.

In 2014, the results showed that there were significant associations between IRS acceptance with educational level, source of IRS information, satisfaction about livestock shelters spraying, and IRS effectiveness $(P<0.05)$. There was significant relationship between the IRS acceptance and the main sources of information on malaria $(P=0.001)$. All householders who heard about the IRS program from the Local Councils and Mosque Speakers, accepted to spray their houses. Spraying rejection was higher for householders informed on the issue by health care workers.

\begin{tabular}{|c|c|c|c|c|c|c|}
\hline \multirow[t]{2}{*}{ Acceptance Rate } & \multicolumn{3}{|c|}{2013} & \multicolumn{3}{|c|}{2014} \\
\hline & Yes & No & PValue & Yes & No & P Value \\
\hline Acceptance of Households About IRS & & & 0.001 & & & 0.3 \\
\hline Konarak & $194(97)$ & $6(3)$ & & $197(98.5)$ & $3(1.5)$ & \\
\hline Chabahar & $212(95.9)$ & $9(4.1)$ & & $221(98.2)$ & $4(1.8)$ & \\
\hline Sarbaz & $200(100)$ & $0(0)$ & & $200(100)$ & $0(0)$ & \\
\hline Saravan & $140(80.9)$ & $33(19.1)$ & & $158(98.8)$ & $2(1.2)$ & \\
\hline Total & $746(94)$ & $48(6)$ & & $776(98.9)$ & $9(1.1)$ & \\
\hline $\begin{array}{l}\text { Acceptance of Households About Livestock } \\
\text { Shelters Spraying }\end{array}$ & & & 0.001 & & & 0.001 \\
\hline Konarak & $165(95.9)$ & $7(4.1)$ & & $164(95.9)$ & $7(4.1)$ & \\
\hline Chabahar & $183(92.4)$ & $15(7.6)$ & & $179(89.1)$ & $22(10.9)$ & \\
\hline Sarbaz & $134(95.7)$ & $6(4.3)$ & & $159(100)$ & $0(0)$ & \\
\hline Saravan & $113(84.3)$ & $21(15.7)$ & & $125(99.2)$ & $1(0.8)$ & \\
\hline Total & $595(92.4)$ & $49(7.6)$ & & $627(95.4)$ & $30(4.6)$ & \\
\hline
\end{tabular}

a Abbreviation: IRS, Indoor Residual Spraying.

Table 5. The Relationship Between Indoor Residual Spraying Acceptance Rate and Satisfaction/Effectiveness of Spraying and Socioeconomic Characteristics of Householders ${ }^{\mathrm{a}}$

\begin{tabular}{|c|c|c|c|c|c|c|}
\hline \multirow[t]{3}{*}{ Variable } & \multicolumn{3}{|c|}{2013} & \multicolumn{3}{|c|}{2014} \\
\hline & \multicolumn{3}{|c|}{ Acceptance } & \multicolumn{3}{|c|}{ Acceptance } \\
\hline & Yes & No & PValue & Yes & No & PValue \\
\hline Gender & & & 0.07 & & & 0.49 \\
\hline Male & $534(93)$ & $40(7)$ & & $469(98.5)$ & $7(1.5)$ & \\
\hline Female & $200(96.2)$ & $8(3.8)$ & & $297(99.3)$ & $2(0.7)$ & \\
\hline Age Category, y & & & 0.4 & & & 0.18 \\
\hline$\leq 29$ & $235(95.1)$ & $12(4.9)$ & & $232(97.9)$ & $5(2.1)$ & \\
\hline $30-59$ & $414(93)$ & $31(7)$ & & $438(99.1)$ & $4(0.9)$ & \\
\hline$\geq 60$ & $96(95)$ & $5(5)$ & & $104(100)$ & $0(0)$ & \\
\hline
\end{tabular}


Sakeni M et al.

\begin{tabular}{|c|c|c|c|c|c|c|}
\hline Education Level & & & 0.006 & & & 0.001 \\
\hline Illiterate & $446(96.1)$ & $18(3.9)$ & & $482(99.4)$ & $3(0.6)$ & \\
\hline Under diploma & $227(90.1)$ & $25(9.9)$ & & $180(99.4)$ & $1(0.6)$ & \\
\hline Diploma & $49(90.7)$ & $5(9.3)$ & & $76(97.4)$ & $2(2.6)$ & \\
\hline University & $17(100)$ & $0(0)$ & & $36(92.3)$ & $3(7.7)$ & \\
\hline Main Jobs & & & 0.001 & & & 0.80 \\
\hline Employee & $26(92.9)$ & $2(7.1)$ & & $21(95.5)$ & $1(4.5)$ & \\
\hline Housewife & $54(94.7)$ & $3(5.3)$ & & $48(100)$ & $0(0)$ & \\
\hline Shopper (Self-employed) & $32(100)$ & $0(0)$ & & $26(100)$ & $0(0)$ & \\
\hline Worker & $93(82.3)$ & $20(17.7)$ & & $128(98.5)$ & $2(1.5)$ & \\
\hline Farmer/Livestock keeper & $347(96.1)$ & $14(3.9)$ & & $350(98.9)$ & $4(1.1)$ & \\
\hline Fishermen & $43(97.7)$ & $1(2.3)$ & & $41(100)$ & $0(0)$ & \\
\hline Others & $151(95)$ & $8(5)$ & & $161(98.8)$ & $2(1.2)$ & \\
\hline Family Member & & & 0.8 & & & 0.4 \\
\hline$\leq 3$ & $226(93.4)$ & $16(6.6)$ & & $241(98.4)$ & $4(1.6)$ & \\
\hline $4-6$ & $337(94.1)$ & $21(5.9)$ & & $342(99.4)$ & $2(0.6)$ & \\
\hline$\geq 7$ & $180(94.7)$ & $10(5.3)$ & & $189(98.4)$ & $3(1.6)$ & \\
\hline Source of IRS Information & & & 0.57 & & & 0.001 \\
\hline Health care workers & $371(98.4)$ & $6(1.6)$ & & $425(99.8)$ & $1(0.2)$ & \\
\hline Malaria officers & $293(97)$ & $9(3)$ & & $347(98.9)$ & $4(1.1)$ & \\
\hline Local councils & $34(100)$ & $0(0)$ & & $0(0)$ & $1(100)$ & \\
\hline Mosque's imams & $22(100)$ & $0(0)$ & & $1(100)$ & $0(0)$ & \\
\hline Others & $2(100)$ & $0(0)$ & & $0(0)$ & $0(0)$ & \\
\hline Satisfaction of Livestock Shelters Spraying & & & 0.001 & & & 0.004 \\
\hline Yes & $560(100)$ & $0(0)$ & & $598(99.2)$ & $5(0.8)$ & \\
\hline No & $33(91.7)$ & $3(8.3)$ & & $26(89.7)$ & $3(10.3)$ & \\
\hline Was IRS Beneficial? & & & 0.001 & & & 0.002 \\
\hline Yes & $698(100)$ & $0(0)$ & & $728(99.7)$ & $2(0.3)$ & \\
\hline No & $46(92)$ & $4(8)$ & & $48(94.1)$ & $3(5.9)$ & \\
\hline Types of Malaria Foci & & & 0.001 & & & 0.55 \\
\hline Cleared-up & $200(100)$ & $0(0)$ & & $216(99.5)$ & $1(0.5)$ & \\
\hline New probable & $123(78.3)$ & $34(21.7)$ & & $155(99.4)$ & $1(0.6)$ & \\
\hline New active & $43(87.8)$ & $6(12.2)$ & & $51(96.2)$ & $2(3.8)$ & \\
\hline Old active & $163(95.9)$ & $7(4.1)$ & & $178(98.3)$ & $3(1.7)$ & \\
\hline Old inactive & $155(99.4)$ & $1(0.6)$ & & $174(98.9)$ & $2(1.1)$ & \\
\hline Building Materials & & & 0.001 & & & 0.70 \\
\hline Cement block & $272(94.8)$ & $15(5.2)$ & & $312(98.1)$ & $6(1.9)$ & \\
\hline Brick & $11(73.3)$ & $4(26.7)$ & & $12(100)$ & $0(0)$ & \\
\hline Stony & $79(100)$ & $0(0)$ & & $79(100)$ & $0(0)$ & \\
\hline Mud brick & $256(89.8)$ & $29(10.2)$ & & $232(99.1)$ & $2(0.9)$ & \\
\hline Shed & $128(100)$ & $0(0)$ & & $138(99.3)$ & $1(0.7)$ & \\
\hline Having Electricity in Their Village & & & 0.04 & & & 0.37 \\
\hline Yes & $646(93.1)$ & $48(6.9)$ & & $737(98.9)$ & $8(1.1)$ & \\
\hline No & $90(100)$ & $0(0)$ & & $39(97.5)$ & $1(2.5)$ & \\
\hline Having Electricity in Their House & & & 0.04 & & & 0.99 \\
\hline Yes & $652(93.1)$ & $48(6.9)$ & & $668(99)$ & $7(1)$ & \\
\hline No & $94(100)$ & $0(0)$ & & $101(99)$ & $1(1)$ & \\
\hline Having TV in Their House & & & 0.001 & & & 0.82 \\
\hline Yes & $376(90.8)$ & $38(9.2)$ & & $628(98.7)$ & $8(1.3)$ & \\
\hline No & $355(97.3)$ & $10(2.7)$ & & $146(99.3)$ & $1(0.7)$ & \\
\hline $\begin{array}{l}\text { Having Cooler (Air conditioner or Evapo- } \\
\text { rative cooler) in Their House }\end{array}$ & & & 0.01 & & & 0.35 \\
\hline Yes & $468(92.3)$ & $39(7.7)$ & & $497(98.6)$ & $7(1.4)$ & \\
\hline No & $261(96.7)$ & $9(3.3)$ & & $259(99.2)$ & $2(0.8)$ & \\
\hline
\end{tabular}


Sakeni $M$ et al.

\section{Discussion}

The study results showed that the overall coverage of vector control interventions by IRS was found to be relatively high, at 94\%. The householders' knowledge about the malaria transmission, acceptance and satisfaction rates on IRS are appropriate to identify the indicators to improve the malaria control programs effectiveness. The results can help the policy makers to make an appropriate decision on interventions of IRS.

In the previous study that was performed from 2008 to 2011, in south-east of Iran, the IRS coverage was $85.12 \%$ (8). The current study results showed that the IRS coverage rate was $96.5 \%$. This result shows that the IRS coverage rate, in that region, is increasing yearly. In comparison with other studies, the spraying percentage was nearly similar to the coverage reported in Zanzibar, Tanzania (95\%) (13) and was higher than in the studies undertaken in Ethiopia (27.8\%) (12) and South Africa (70\%) (1). The high IRS coverage is a key mechanism for reducing the malaria prevalence and decreasing the risk of malaria outbreak (13). Expanding the IRS coverage rate to $\geq 80 \%$ of households seems to be the most effective to prevent transmission of infection and control malaria $(5,8,11)$.

Our data showed that rural residents of these districts have demonstrated a better knowledge about the malaria transmission. The majority of the householders (95.3\%) associated mosquito bites with malaria transmission that was similar to other reports from different parts of the world $(3,15)$ and was higher than reported in Southern Mexico (48\%) (11) and Ethiopia (56.1\%) (12). The high knowledge on malaria preventions, transmission and treatment has considerable impact on the effectiveness of malaria control programs and, therefore, public health education programs should always be implemented to increase the existing knowledge of the entire population for an adequate length of time, to be effective (3).

Among the most acknowledged means of personal protection against the mosquito's bites, the majority mentioned the use of insecticidal bed nets, as a preventing way against mosquito's bites, which is in agreement with what has been reported previously in Zanzibar, Tanzania (13), Northwestern Tanzania (3) and Ethiopia (82.2\%) (12).

Concerning IRS acceptance, most of the respondents (94\%) agreed for their houses to be sprayed during the spraying campaign and this coverage rate of house-spraying is sufficient to prevent human-vector contact and reduce the malaria transmission (11). A similar finding was reported from Northwestern Tanzania and Southern Mexico $(3,15)$. This acceptance rate was lower than the study conducted by Rodriguez et al. in Southern Mexico, with 97.6\% (11), and was higher than the study in South Africa (1). Malaria control, based on IRS, is deeply associated with willingness of households to accept the spraying of residual insecticides during the spraying campaign (3).

The majority of respondents reported that they were informed about the program one day before the spray- ing and the most common sources of information were health care workers and malaria officials. The result was similar with another study from South Africa (1). In this study region, the main information sources were different from the studies of Northwestern Tanzania (3) and Ethiopia (12), in which residents received the majority information by radio programs.

Concerning their personal opinion on benefits of IRS, the majority of respondents reported that the most significant reasons for accepting the IRS was reducing the malaria transmission and mosquito abundance, by killing malaria mosquitoes. Similar findings have been reported in Northwestern Tanzania and South Africa (1, 3). However, in the Southern Mexico study, only 3\% of respondents related it directly to the prevention of malaria transmission (11).

The reasons for IRS refusal were the discoloring of inner house walls, by the insecticide, and difficulty in furniture's movement. The responses were different from other reports in Northwestern Tanzania and South African studies $(1,3)$. In Northwestern Tanzania, the main reason of IRS refusal was the bad smell of insecticides (3), while in the South African study, the two main reasons for non-spraying were that nobody visited the house to spray or that nobody was at home (1). The study showed that householders with low socio-economic characteristics had higher IRS acceptability rate. The results were different from the study that reported the rates in Zanzibar, Tanzania (13).

In the present study, the low educational level of residents represented the study limitation. Training the native health care workers to ask them the questions with local language and high cooperation through residents and authorities were the study strengths.

In summary, in terms of public health, the study showed that IRS coverage and acceptance were high, which are essential in reaching malaria elimination. The information on malaria transmission and knowledge of prevention ways showed that householders were approximately familiar with malaria control activities, conducted by the health care service. High IRS perception and cooperation can help to improve the IRS and malaria control program performance. The study showed that all householders that heard about the IRS program through local councils and Mosque's Imams agreed to spray their houses. Therefore, the involvement of credible community leaders and close relationship between health care services with local reliable people or Mosque's Imams can help to achieve high IRS coverage and cooperation, through householders.

\section{Acknowledgments}

The authors would like to thank to all data collection teams, field supervisors, and the household heads, who participated in the study. Our special thanks go to the Konarak, Chabahar, Sarbaz, and Saravan districts Health Departments for their assistance to perform the study. 


\section{Footnote}

Authors' Contributions:Mohammad Sakeni participated in the design and analysis of the study, conducted the data collection teams, and drafted the manuscript. Alireza Khorram participated to data collection and contributed in the study design. Reza Majdzadeh participated in the design of the study, performed the study analysis, and revised the manuscript. Ahmad Raiesi organized the field activities, conducted the data collection teams and participated in the study design. All the authors read and approved the manuscript.

\section{References}

1. Hlongwana KW, Zitha A, Mabuza AM, Maharaj R. Knowledge and practices towards malaria amongst residents of Bushbuckridge, Mpumalanga, South Africa. Afr J Primary Health Care Famil Med. 2011;3(1):9 pages.

2. Azizi K, Moemenbellah-Fard MD, Khosravani-Shiri M, Fakoorziba MR, Soltani A. Lethal and Residual Effects of Lambdacyhalothrin, Deltamethrin and Cyfluthrin Insecticides on Adult Mosquitoes of Anopheles stephensi Liston (Diptera: Culicidae) on Different Surfaces. J Health Sci Surveil Sys. 2014;2(1):30-5.

3. Mazigo HD, Obasy E, Mauka W, Manyiri P, Zinga M, Kweka EJ, et al. Knowledge, Attitudes, and Practices about Malaria and Its Control in Rural Northwest Tanzania. Malaria Res Treat. 2010;2010:19. doi:10.4061/2010/794261.

4. Keating J, Locatelli A, Gebremichael A, Ghebremeskel T, Mufunda J, Mihreteab S, et al. Evaluating indoor residual spray for reducing malaria infection prevalence in Eritrea: Results from a community randomized control trial. Acta Tropica. 2011;119(2-3):10713. doi:10.1016/j.actatropica.2011.04.015. [PubMed:21565149]

5. World Health Organization. Indoor residual spraying; Use of indoor residual spraying for scaling up global malaria control and elimination. Global Malaria Programme. 2006. Available from: http:/ whqlibdoc.who.int/hq/2006/WHO_HTM_MAL_2006.1112_eng. pdf?ua $=1$.

6. Kleinschmidt I, Schwabe C, Shiva M, Segura JL, Sima V, Mabunda SI, et al. Combining indoor residual spraying and insecticidetreated net interventions. Am J Trop Med Hyg. 2009;81(3):519-24. [PubMed: 19706925]

7. Kaufman MR, Rweyemamu D, Koenker H, Macha J. "My children and I will no longer suffer from malaria": a qualitative study of the acceptance and rejection of indoor residual spraying to prevent malaria in Tanzania. Malaria J. 2012;11(1):220. doi: 10.1186/1475-2875-11-220.

8. Nejati J, Mahjoob M, Kiyani M, Keyhani A, Hasanzehi A. Status of Indoor Residual Spraying by Deltamethrin in Malaria Elimination Program, Southeastern Iran. Iran J Toxicol. 2012;6(16):600-4.

9. GBCHealth's. Private Sector Opportunities in Indoor Residual Spraying and Malaria Control in West Africa, The West Africa Malaria Workshop. Private Sector Opportunities. 2013. Available from: http://www.gbchealth.org/wp-content/uploads/2014/03/Private_Sector_Opportunities_in_IRS_and_Malaria_Control_in_West_Africa.pdf.

10. Steinhardt LC, Yeka A, Nasr S, Wiegand RE, Rubahika D, Sserwanga A, et al. The Effect of Indoor Residual Spraying on Malaria and Anemia in a High-Transmission Area of Northern Uganda. Am J Trop Med Hygiene. 2013;88(5):855-61. doi:10.4269/ajtmh.12-0747.

11. Rodriguez AD, Penilla RP, Henry-Rodriguez M, Hemingway J, Francisco Betanzos A, Hernandez-Avila JE. Knowledge and beliefs about malaria transmission and practices for vector control in southern Mexico. Salud Publica Mex. 2003;45(2):110-6. [PubMed: 12736989]

12. Gobena T, Berhane Y, Worku A. Women's knowledge and perceptions of malaria and use of malaria vector control interventions in Kersa, eastern Ethiopia. Glob Health Act. 2013;8(1) doi: 10.3402/ gha.v6io.20461.

13. Beer N, Ali AS, Shakely D, Elfving K, Al-Mafazy AW, Msellem M, et al. High effective coverage of vector control interventions in children after achieving low malaria transmission in Zanzibar, Tanzania. Malaria J. 2013;12(1):38. doi:10.1186/1475-2875-12-38.

14. World Health Organization. Indoor Residual Spraying. An Operational Manual For Indoor Residual Spraying (IRS) For Malaria Transmission Control And Elimination. 2013. Available from: http://www.who. int/iris/bitstream/10665/80126/1/9789241505123_eng.pdf?ua=1.

15. Sanjana P, Barcus MJ, Bangs MJ, Ompusunggu S, Elyazar I, Marwoto $\mathrm{H}$, et al. Survey of community knowledge, attitudes, and practices during a malaria epidemic in central Java, Indonesia. Am J Trop Med Hyg. 2006;75(5):783-9. [PubMed: 17123966]

16. Munguambe K, Pool R, Montgomery C, Bavo C, Nhacolo A, Fiosse L, et al. What drives community adherence to indoor residual spraying (IRS) against malaria in Manhiça district, rural Mozambique: a qualitative study. Malaria J. 2011;10(1):344. doi: 10.1186/1475-2875-10-344

17. Tatem AJ, Smith DL. International population movements and regional Plasmodium falciparum malaria elimination strategies. Proceedings of the National Academy of Sciences. 2010;107(27):12222-7. doi:10.1073/pnas.1002971107.

18. Tusting LS, Ippolito MM, Willey BA, Kleinschmidt I, Dorsey G, Gosling RD, et al. The evidence for improving housing to reduce malaria: a systematic review and meta-analysis. Malaria J. 2015;14(1) doi:10.1186/s12936-015-0724-1. 